\title{
Prescription pattern of anti-epileptic medications in a tertiary care centre
}

\author{
Shilpa B. N. ${ }^{1}$, Sushma H. K. ${ }^{2, *}$, Latha S. $^{3}$, Shashikala G. H. ${ }^{4}$ \\ ${ }^{1,3}$ Post Graduate, ${ }^{2}$ Assistant Professor, ${ }^{4}$ Professor \& HOD, Dept. of Pharmacology, JJM Medical College, Davangere, Karnataka, \\ India
}

*Corresponding Author:

Email: drhksushma1987@gmail.com

\begin{abstract}
Introduction: The objective of this study was to study the prescribing pattern of antiepileptic medications in patients with epilepsy in a tertiary care hospital.

Materials and Methods: This was an observational study, conducted in psychiatry outpatient department (OPD) of Bapuji attached to Jagadguru Jayadeva Murugarajendra medical college and CG Hospital, Davangere. Patients demographic details, clinical diagnosis, type of epilepsy, type of AED used, drug dose and frequency of 100 outpatients who attended the psychiatry OPD was recorded.

Results: A total of 100 prescriptions were analysed with more number of males (62\%) than females (38\%). Epilepsy was more commonly seen in the patients of age group of 20-40 years (52\%) and GTCS was diagnosed in 79\% of the patients followed by partial seizures and other types. Majority of them received monotherapy (67\%) with most commonly prescribed AED phenobarbitone $(28 \%)$ followed by phenytoin $(16 \%)$, levetiracetam $(12 \%)$, carbamazepine $(8 \%)$, lorazepam (2\%) and ethosuximide (1\%). 33\% of the patients received combined therapy, most commonly used two drug combination was phenobarbitone with phenytoin and three drug combination was with phenobarbitone, phenytoin and carbamazepine. 19 patients reported adverse events, most common were related to CNS.

Conclusion: In our study, majority of the patients were males with age group 20-40 yrs and most commonly used drugs were conventional AEDs as monotherapy with phenobarbitone, phenytoin and levetiracetam.
\end{abstract}

Keywords: Epilepsy, Anti Epileptic Drug (AED), Monotherapy, Combined therapy, Prescribing pattern.

\section{Introduction}

Epilepsy is the most common neurological disorder characterised by recurrent seizures due to abnormal excessive synchronous neuronal activity in the brain. ${ }^{1,2}$ Epilepsy affects 0.5 to $1 \%$ of the world's population (50 million people worldwide). 1 in 26 people will develop epilepsy in their lifetime. ${ }^{3}$ It is estimated that the overall prevalence of epilepsy in India is $5.59-10$ per $1000 .^{3}$

In most cases, epilepsy has no identifiable cause (idiopathic). Other underlying causes include genetic abnormality and secondary to head injury, infections, ischemia, mass lesions or exposure to drugs and toxins. ${ }^{1,4}$

Uncontrolled seizures are associated with physical and psychosocial morbidity, dependent behavior, poor quality of life and an increased risk of sudden unexpected death. Therefore treatment with antiepileptic drugs (AED) is mandatory once the patient is diagnosed to be a case of epilepsy. ${ }^{5}$

Antiepileptic drugs (AEDs) are the mainstay of the therapy for epilepsy, despite the development in recent years of new therapeutic options, such as brain stimulation or surgery. In the last years, several pharmaco epidemiological studies documented a growing trend in AED use, particularly in elderly patients. $^{6}$

The choice of most appropriate antiepileptic drug depends on type of seizures and age of patient. Seizure control may be achieved by monotherapy in about $80 \%$ of the patients, while other $20 \%$ requiring two to three AEDs. ${ }^{7,8}$

In spite of continued emergence of newer drugs like vigabatrin, gabapentin, lamotrigine, topiramate, levetiracetam, felbamate, oxcarbazepine, lacosamide, the response to antiepileptic therapy is still unpredictable and unsatisfactory. These newer AEDs are not found to be superior to major standard anticonvulsant drugs such as phenytoin, carbamazepine and sodium valproate. They are merely serving as "addon" drugs. The physicians and even the neurologists are in a dilemma and vary from one another in selecting the most appropriate drug in a particular type of epilepsy. ${ }^{9,10}$

When choosing an AED, factors such as mechanism of action, ease of dosing, efficacy, long term adverse effects, neuropsychiatric profile, sedative burden, interaction with other medications, seizure types and other co-morbid conditions should be considered. ${ }^{11,12}$

With the advent of newer antiepileptic agents, there have been major changes in prescribing pattern in epilepsy. By assessing the current pattern of prescription in the country based on the age, mono/polytherapy, use of newer AED's can ensure the rational use of medication and improve patient compliance. ${ }^{13}$

The aim of this study was to analyse use of various AEDs and type of epilepsy prevalent in our population. 


\section{Objective}

1. To assess the AEDs prescribing pattern in epilepsy.

2. To assess the prevelance of different types of epilepsy in Epilepsy patients.

3. To assess the drug regimen (single / multiple AEDs) used in patients.

\section{Materials and Methods}

It was an observational study, conducted at psychiatry and medicine outpatient department (OPD) in Bapuji Hospital, attached to JJM medical college from june to august 2017 (3 months). Adult outpatients who have been diagnosed to have epilepsy were identified and prescribing pattern was studied. Approval was obtained from institutional ethical committee with ethical clearance number: JJMMC/IEC/58-2016.

\section{Inclusion Criteria}

1. More than 15 years of age.

2. Both sex, male and female.

3. Idiopathic epilepsy.

\section{Exclusion Criteria}

1. Pregnant and lactating woman

Totally 100 prescriptions were collected randomly over a period of 3 months. Patients demographic details, clinical diagnosis, type of epilepsy, type of AED used, drug dose and frequency will be recorded. Average number of drug per prescription were calculated. Prescription of all patients was entered in a preformed proforma and was analyzed using descriptive statistics.

\section{Statistical Analysis}

An observational study was done. A descriptive statistical analysis was applied in the present study.

\section{Results}

Socio-demographic details of subjects: In the present study, out of 100 patients 62 patients were male and 38 patients were females. Epilepsy was more commonly seen in the patients of age group of 20-40 years.(Table 1) $56 \%$ of the patients were educated and $58 \%$ of the patients were employed (Table 2). Family history of epilepsy was seen in $28 \%$ of the patients. (Table 3 )

Types of epilepsy: Among the total prescriptions analysed, $79 \%$ of patients were diagnosed as GTCS, $11 \%$ of patients as partial seizure, $4 \%$ as myoclonic seizure, $5 \%$ as secondary seizures and $1 \%$ with Absence seizure. (Fig. 1)

Comparison of mono and poly therapy: Out of 100 patients, majority of them received monotherapy with various drugs (67\%). About $33 \%$ of the patients received combination therapy with two or more drugs. (Fig. 1)
Commonly used AEDs in monotherapy and combination therapy: Out of 67 patients who were on monotherapy, most commonly prescribed AED was phenobarbitone $(28 \%)$ followed by phenytoin $(16 \%)$, levetiracetam (12\%), carbamazepine (8\%), lorazepam (2\%) and ethosuximide (1\%) (Fig. 2)

In combination therapy, most commonly used two drug combination was phenobarbitone with phenytoin and three drug combination was with phenobarbitone, phenytoin and carbamazepine which is depicted in Fig. 3

Frequency of adverse events: Among 100 patients who were on AEDs, 19 of them reported adverse events. Most common adverse events were related to CNS (9) and included sedation, head ache and dizziness. 4 patients who were receiving phenytoin reported gingival hyperplasia. Gastrointestinal disturbance was reported by 4 patients. 1 patient reported weight gain. (Table 3)

\section{Discussion}

Prescription pattern studies play a key role in helping the healthcare system to understand, interpret and improve the prescription, administration and use of medications, whose principal aim is to facilitate rational use of drugs. Patient files and computer registries are widely used as instruments for collecting information on drug. ${ }^{15}$

Epilepsy is a chronic condition which impair quality of life due to physical, psychological and socioeconomic consequences. The prime requirements are a complete diagnosis, selection of optimal treatment, and counselling appropriate to individual needs. ${ }^{16}$

The aim of treatment is cessation of seizures without side effects. Pharmacological factors influencing the choice of drug include efficacy, toxicity, and ease of use, all of which should be considered with respect to individual patient needs. ${ }^{16}$

In this study, a total of 100 prescriptions of epilepsy were studied. By the analysis of sociodemographic data, it was found that percentage of male patients $(62 \%)$ was higher than percentage of female patients (38\%) (Table 1). Male preponderance is seen in gender distribution in our study, which is similar to reports from other studies in countries of Asia. ${ }^{17}$

Maximum patients in this study were of age group $20-40$ years $(52 \%)$ followed by $>40$ years $(32 \%)$ and $10-20$ years $(16 \%)$. Bimodal distribution is seen with the incidence of epilepsy. With a peak incidence in first decade and then in elderly patients. ${ }^{18}$ In India, most of the population is young, which might be the reason for missing peak in elderly patients in our study ${ }^{19}$. Family history of epilepsy is present in $28 \%$ of patients. (Table 3)

The most common type of epilepsy seen in this study was GTCS (79\%) which is similar to other study 
done by sachchidanad Pathak et al. ${ }^{20}$ Followed by partial seizures (11\%), secondary seizures (5\%), myoclonic seizures (4\%) and absence seizures (1\%). (Fig. 1)

Monotherapy is mostly preferred to minimise the risk of adverse drug reactions, dose related toxicity, drug interactions, non compliance and economic burden. $^{21}$

In our study majority of the patients were prescribed monotherapy which is in accordance with many other studies.22 $67 \%$ of patients were on monotherapy and $33 \%$ of patients were on combined therapy (Fig. 2). Phenobarbitone (28\%) was the most commonly prescribed AED as monotherapy in our study followed by phenytoin (16\%). These two drugs were supplied freely by the government. Other drugs are levetiracetam (12\%), carbamazepine ( $8 \%)$, lorazepam (2\%) and ethosuximide (1\%). (Fig. 3).

Polytherapy has many disadvantages like non compliance, increased incidence of adverse effects and also quality of life will be affected but it is unavoidable in few set of patients who are not responding to monotherapy. ${ }^{23,24}$ In combination therapy, most commonly used two drug combination was phenobarbitone with phenytoin $(23 \%)$ as these drugs are of low cost and easily affordable, followed by three drug combination with phenobarbitone, phenytoin and carbamazepine (6\%). (Fig. 4).

The newer AEDs used in this study are Levetiracetam and Topiramate. Newer AED were not commonly prescribed due to higher cost and non availablity in government supply, as they are still not included in Essential Drug List. ${ }^{20}$

Adverse events to antiepileptic drugs were seen in 19 patients, most of them were related to CNS that included sedation, head ache and dizziness. Drug specific side effects like gingival hyperplasia was seen in 4 patients who were on phenytoin.

Table 1: Age and Sex wise distribution

\begin{tabular}{|l|c|c|c|}
\hline \multicolumn{1}{|c|}{ Age } & Male & Female & Total \\
\hline $10-20$ Yrs & 11 & 5 & 16 \\
\hline $20-40$ Yrs & 27 & 15 & 52 \\
\hline$>40$ & 24 & 18 & 32 \\
\hline Total & 62 & 38 & 100 \\
\hline
\end{tabular}

Table 2: Educational and Employment status

\begin{tabular}{|l|c|}
\hline Educated & 56 \\
\hline Uneducated & 44 \\
\hline Employed & 58 \\
\hline Unemployed & 42 \\
\hline
\end{tabular}

Table 3: Family history

\begin{tabular}{|l|c|c|}
\hline Family History & Present & Absent \\
\cline { 2 - 3 } & 28 & 72 \\
\hline
\end{tabular}

Table 4: Adverse events

\begin{tabular}{|l|c|}
\hline \multicolumn{1}{|c|}{ Adverse events } & No. of patients \\
\hline CNS related & 9 \\
\hline $\begin{array}{l}\text { Gastrointestinal } \\
\text { disturbance }\end{array}$ & 5 \\
\hline Gingival hyperplasia & 4 \\
\hline Weight gain & 1 \\
\hline
\end{tabular}

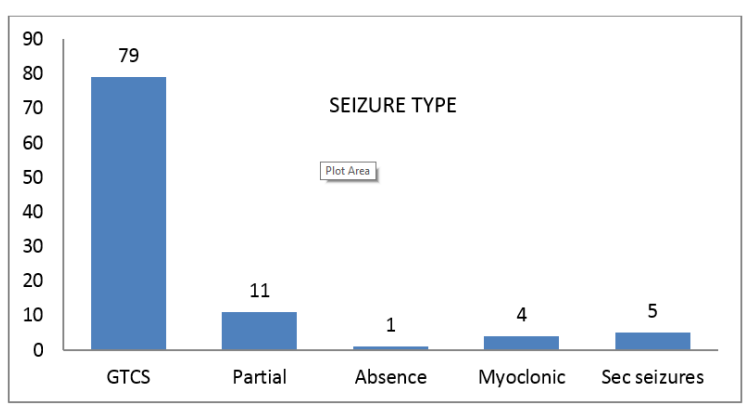

Fig. 1: Types of seizure

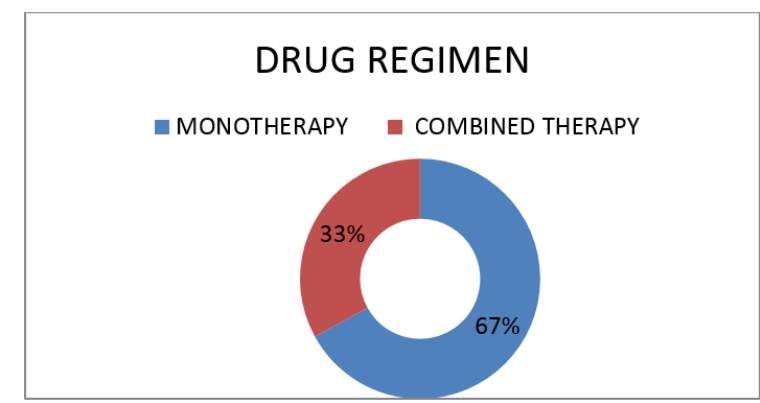

Fig 2: Drug Regimen

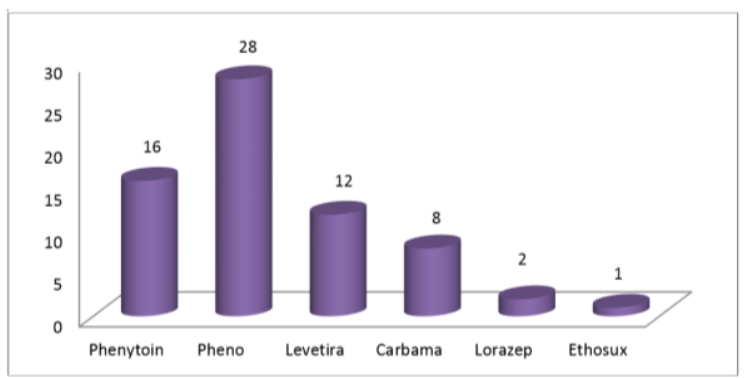

Pheno: Phenobarbitone, Levetira: Levetiracetam, Carbama: Carbamazepine, Lorazep: Lorazepam Ethosux: Ethosuximide

Fig 3: Drugs used in monotherapy

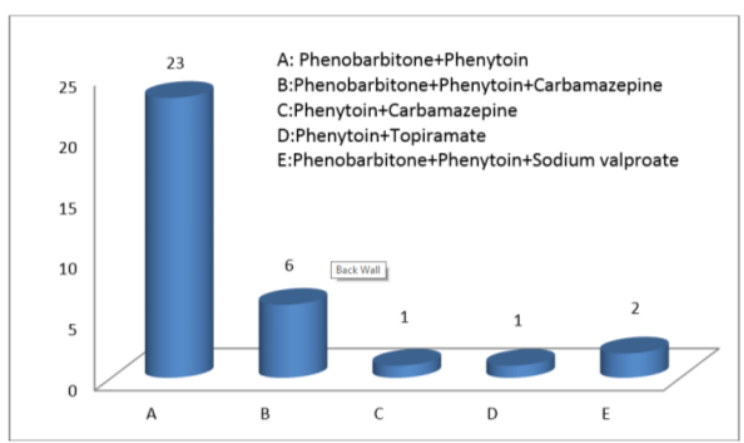

Fig 4: Drugs used in combined therapy 


\section{Conclusion}

Our study on prescription pattern of epilepsy in a tertiary care hospital showed male preponderance with majority of the patients in age group 20-40 yrs. GTCS was the commonest type of epilepsy and monotherapy with conventional AEDs like phenytoin and phenobarbitone was preferred in most of the patients. Newer antiepileptics used were levetiracetam and topiramate. Since there are no specific guidelines for the usage of AED in India, the rationality in the prescription is variable and poor. Hence our study concluded that Prescription pattern in our study is relevant with current trend.

\section{References}

1. DH Lowenstein, seizure and epilepsy.DL Kasper.Harrison's principles of internal medicine, $19^{\text {th }}$ ed.New York.Mc Graw Hill education;p.2542-59

2. Fisher RS, Boas WvE, Blume W, Elger C, Genton P, Lee $P$ et al . Epileptic Seizures and Epilepsy Definition Proposed by ILEA and IBE. Eplepsia.2005;46 (4):470-2

3. De Boer HM, M ula M, Sander JW. The Global Burden and Stigma of Epilepsy, Epilepsy Behav. 2008; 12:540-6.

4. Dichter MA. Emerging Concepts in the pathogenesis of Epilepsy and Epileptogenesis.Archives of Neurology 2009;66:443-7.

5. Sridharan R, Murthy BN. Prevalence and pattern of epilepsy in India.Epilepsia.1999;40:631-6

6. Brodie MJ. Medical therapy of epilepsy: When to initiate treatment and when to combine? Journal of Neurology. 2005; 252:125-30.

7. Tsiropoulos I, Gichangi A, Andersen M, Bjerrum L, Gaist D, Hallas J. Trends in utilization of antiepileptic drugs in Denmark.Acta Neurol Scand 2006; 113: 405-11. Erratum in: Acta Neurol Scand 2006;114:70.

8. Uiji SG, Uiterwaal CS, Aldenkamp AP, et al. Adjustment of treatment increases quality of life in patients with epilepsy: a randomized controlled pragmatic trial. EurJNeurol2009;16:1173-7.

9. Arul Kumaran KSG, Palanisami S, Rajasekharan A. A study on drug use evaluation of anti epileptics at a multi specialty tertiary care teaching hospital. IntJ Pharm Tech Res 2009;1(4):1541-7.

10. Vining E. P. (1994) Pediatric seizures. Emerg Med Clin, North Am, 12,973-88.

11. HL Sharma, KK Sharma. Principles of Pharmacology. $2^{\text {nd }}$ edition. Hyderabad;Paras Medical Publisher;2015

12. Ochoa JG, Riche W. Antiepileptic drugs. E medicine.medscape.com 2009;1-39.

13. Clinical Practice Guidelines. Epilepsy in adults. Singapore Epilepsy Society 2007;1-51

14. Charles BH, Linda MS. Opportunities responsibility in pharmaceutical care. American Journal of Hospital Pharmacy. 1990;47(3):533-4.

15. Sachdeva PD, Patel BG. Drug utilization studies-scope and future perspectives. Int J Pharm Bio Res. 2010;1(1):11-7.

16. Smith D, Chadwick D THE MANAGEMENT OF EPILEPSY Journal of Neurology, Neurosurgery \& Psychiatry 2001;70:ii15-ii21.

17. Lim SH, Tan EK. Pattern of anti epileptic drug usage in tertiary referral hospital in Singapore. Neurological Journal of South East Asia. 1997;2(24):77-85.

18. Caprio A, Hauser WA. Epilepsy in the developing world. Current Neurology and Neuroscience Reports. 2009;9(4):319-26
19. Mac TL, Tan DS, Quet F, Odermatt P, Preux PM, Tan CT. Epidemiology, etiology and clinical management of epilepsy in Asia: a systematic review. The Lancet Neurology. 2007;6(6):533-43.

20. Sachchidanand Pathak, Lalit Singh, Tanuja Singh, S.K. Sharma, "Prescribing patterns of Anti-epileptic drug in different age group in India". Journal of Drug Discovery and Therapeutics;2013,1(7),69-75

21. Bhatt KM, Malhotra SD, Patel KP, Patel VJ. Drug utilization in pediatric neurology outpatient department: A prospective study at a tertiary care teaching hospital. Journal of Basic Clinical Pharmacy 2014; Vol5: Page no.68-73.

22. Shobhana Mathur, Sumana Sen, L Ramesh, Satish Kumar M. Utilization Pattern of antiepileptic drugs and their adverse effects, in a teaching hospital. Asian Journal of pharmaceutical and Clinical Research. 2010;3(1):55-59.

23. Vazquez B. Monotherapy in epilepsy role of the newer antiepileptic drugs. Arch Neurol2004; 61(9):1361-5.

24. Thomas SV, Koshy S, Sudhakaran Nair CR, Sarma SP. Frequent seizures and polytherapy can impair quality of life in persons with epilepsy. Neurol India 2005;53(1):4650. 